\title{
EFFECT OF FILTRATION COEFFICIENT DETERMINATION METHOD ON THE SCALE EFFECT IN WATER-SATURATED FINE-GRAINED SOILS
}

\section{T.N Rosine ${ }^{1}$, T. Toma Sabbagh ${ }^{2}$}

${ }^{1}$ Ph.D. student, Civil Engineering Research Group, The University of Salford, School of Computing, Science and Engineering, Newton Building, Salford, Greater Manchester, M5 4WT, UK. Email: t.n.rosinelarissal@edu.salford.ac.uk

${ }^{2}$ Lecturer, Civil Engineering, The University of Salford, School of Computing, Science and Engineering, Newton Building, Salford, Greater Manchester, M5 4WT, UK. Email:

t.toma@salford.ac.uk

\begin{abstract}
The coefficient of permeability is an imperative engineering property of soils and it is used in some engineering problems such as modelling of underground flow. Its determination based on measured characteristics can significantly reduce the conclusion aspect. The coefficient of permeability can be derived from the following measured parameters: coefficient of consolidation $\left(c_{v}\right)$, coefficient of compressibility $\left(a_{v}\right)$, coefficient of volume compressibility $\left(m_{v}\right)$, average particle size $\left(D_{10}\right)$ and void ratio $(e)$. In the current study, the coefficient of permeability was calculated from the one-dimensional consolidation tests and previous researchers derived formula. The outcome was compared with the estimated value within PLAXIS. A simulation of both permeability parameters were modelled in PLAXIS in terms of sample scale effect using the Mohr-Coulomb (MC) model. The sample scale effect was due to the variation in the diameter to height ratio of the soil profile. The results showed that there was a significant difference in the soil behaviour between the calculated and estimated permeability. The excess pore pressure at different scale was found to be well represented using the estimated permeability as compared to the calculated value that is due to the variability of the permeability coefficient during consolidation and scale effect.
\end{abstract}

Keywords: Coefficient of Permeability, Consolidation, Excess pore pressure, Fine-grained soil, Scale effect

\section{Introduction}

Since water movement within the soil is through void spaces, the larger the void space, the greater the permeability. Coarse-grained soils specifically sand, exhibit higher permeability as compared to the fine-grained soil like clay, which has a lower permeability [1]. Hence, the permeability of soils depends on particle size, structure of soil mass, the shape of soil and void 
ratio, with the major factor being the particle size and void ratio. There are numerous methods derived over the past few decades in obtaining the coefficient of permeability $(k)$ of finegrained soils in the laboratory using the falling head method and one-dimensional test (permeameter).

Over the past few decades, several models were developed to show the relationship between permeability and particle size [2]. [3] mentioned that, [4] performed statistical power regression analyses on 19 sets of data and the coefficient of permeability $(k)$ was found to have a relationship with soil grain size as shown in equation 1 :

$$
k=c D_{10}^{1.65} \text { to } 1.85
$$

where $c$ is a constant and $D_{10}$ is the average particle size.

The limitation of using equation 1 is that it was developed on sand soils and hence gives inaccurate results when applied on fine-grained soils [3]. However, [3] developed a new relationship between permeability and grain size using regression analysis as shown in equation 2:

$$
k=\left(D_{10}\right)^{2} *\left(e^{3}\right)
$$

where $k$ is the coefficient of permeability $(\mathrm{m} / \mathrm{s}), D_{10}$ is the average particle size $(\mathrm{mm})$, to such an extent that $10 \%$ of the particles are finer than that size (dimensionless) and $e$ is the void ratio (dimensionless). Also to equation 1 and 2, the soil permeability can also be obtained using the relationship between $c_{v}, m_{v}$ and $a_{v}$.

$$
k=c_{v} m_{v} \gamma_{w}
$$

$$
k=\frac{c_{v} a_{v} \gamma_{w}}{1+e}
$$

where $c_{v}$ is the coefficient of consolidation $\left(\mathrm{m}^{2} / \mathrm{yr}\right), m_{v}$ is coefficient of volume compressibility $\left(\mathrm{m}^{2} / \mathrm{MN}\right), a_{v}$ is the coefficient of compressibility, $e$ is the void ratio and $\gamma_{w}$ is the unit weight of water $\left(\mathrm{kN} / \mathrm{m}^{3}\right)$. Equating equation 2 and 3, a new equation for $c_{\nu}$ is shown below:

$$
c_{v}=\frac{D_{10}^{2} x e^{3}}{m_{v} \gamma_{w}}
$$

The effect of the coefficient of permeability on the scale effect ( $D / H$ ratio) was not previously investigated. However, [5] showed that $D / H$ ratio has a significant influence on the compressibility parameters taking into consideration the estimated $k$ value in PLAXIS. The current study shows the impact of the estimated and calculated values using equations 2 and 3 . 
The outcome is related to the standard $D / H$ ratio recommended for consolidation analysis by the British and American standard.

\section{Diameter to height ratio scale}

Series of Oedometer tests were conducted at different $D / H$ ratio as depicted in Table 1 with the soil properties shown in Table 2. The Kaolin clay used was provided by Cornwall Council England. For valid comparison in the $D / H$ ratio, the average of the initial moisture content was considered. The sample preparation and test setup as described in the British and American standard [6] and [7] were adopted. The test was run over a period of 24 hours at certain load increments $(55-276 \mathrm{kPa})$ under double drainage. Data were obtained using a computerised system connected to each Oedometer test with an accuracy of $\pm 0.1 \%$. The system was able to read data from six channels simultaneously. During the consolidation tests, the coefficient of permeability $(k)$ was not measured due to the lack of facilities but was calculated from previous researcher's derivations.

Table 1: Scale range Oedometer tests [5]

\begin{tabular}{|c|c|c|c|c|c|c|c|c|c|c|}
\hline D/H & 0.5 & 1 & 1.2 & $2(\mathrm{a})$ & $2(\mathrm{~b})$ & 3 & 4 & 5 & 6.5 & 11 \\
\hline Diameter (mm) & 100 & 150 & 250 & 150 & 250 & 250 & 100 & 150 & 150 & 250 \\
\hline Height (mm) & 200 & 130 & 200 & 80 & 130 & 80 & 23 & 30 & 23 & 23 \\
\hline Tests & $\mathrm{T} 1$ & $\mathrm{~T} 2$ & $\mathrm{~T} 3$ & $\mathrm{~T} 4$ & $\mathrm{~T} 5$ & $\mathrm{~T} 6$ & $\mathrm{~T} 7$ & $\mathrm{~T} 8$ & $\mathrm{~T} 9$ & $\mathrm{~T} 10$ \\
\hline Initial moisture & $91 \%$ & $74 \%$ & $55 \%$ & $65 \%$ & $55 \%$ & $55 \%$ & $80 \%$ & $60 \%$ & $59 \%$ & $64 \%$ \\
\hline Average & \multicolumn{10}{|c|}{$66 \%$} \\
\hline
\end{tabular}

Table 2: Soil Properties summary [5]

\begin{tabular}{|c|c|c|c|c|c|c|}
\hline & $\boldsymbol{L L}$ & $\boldsymbol{P L}$ & $\boldsymbol{P I}$ & $\boldsymbol{G}_{\boldsymbol{s}}$ & $\boldsymbol{c}_{\boldsymbol{u}}\left(\boldsymbol{k N} / \boldsymbol{m}^{2}\right)$ & Mineralogy \\
\hline Kaolin & $63 \%$ & $32.4 \%$ & $30.6 \%$ & 2.6 & $0.28-12$ & Kaolinite and Quartz \\
\hline
\end{tabular}

where LL is the liquid limit (\%), PL is the plastic limit (\%), PI is the plasticity index (\%), $G_{s}$ is the specific gravity and $c_{u}$ is the undrained shear strength $\left(\mathrm{kN} / \mathrm{m}^{2}\right)$

\section{Finite element model}

To model the saturated fine-grained soil, the coefficient of permeability is vital for PLAXIS as it uses this parameter during the consolidation analysis. The Mohr-Coulomb $(M C)$ model is used with soil void ratio varying from 1.2 to 2.5 . The calibration of the finite element model with the experimental data is found in [5]. 


\subsection{Coefficient of permeability model parameters}

The one-dimensional model was completed using an axisymmetric and discretized 16 nodes element. The young's modulus was assumed to be $1000 \mathrm{kN} / \mathrm{m}^{2}$, and the estimated coefficient of permeability $(k)$ was employed in PLAXIS with a constant value of $5.5 \times 10^{-7} \mathrm{~m} / \mathrm{s}$. The estimated $k$ value in PLAXIS was gained using the inputted initial void ratio. The boundary conditions were set as permeable at both the top and bottom of the soil profile with the side being impermeable. The vertical load was applied in double increments to achieve comparative curve to the experimental data. The calculated $k$ values are shown in Table 3.

Table 3: Calculated coefficient of permeability $\left(\mathbf{k}_{\mathbf{c}}\right)$

\begin{tabular}{|c|c|c|c|c|c|c|c|c|c|c|}
\hline Scale & $\begin{array}{c}D / H \\
0.5 \\
\end{array}$ & $D / H 1$ & $\begin{array}{c}D / H \\
1.2 \\
\end{array}$ & $\begin{array}{l}D / H \\
2(a) \\
\end{array}$ & $\begin{array}{l}D / H \\
2(b) \\
\end{array}$ & $\mathrm{D} / \mathrm{H} 3$ & $D / H 4$ & D/H 5 & $\begin{array}{c}D / H \\
6.5 \\
\end{array}$ & $D / H 11$ \\
\hline$k_{c}^{2}\left(x 10^{-6}\right)$ & 1.28 & 0.61 & 0.67 & 0.52 & 0.60 & 0.14 & 0.71 & 0.29 & 0.35 & 0.35 \\
\hline$k_{c}^{3}\left(x 10^{-9}\right)$ & 0.023 & 0.00094 & 0.00064 & 0.00019 & 0.00012 & 0.00024 & 0.00072 & 0.00045 & 0.00041 & 0.00014 \\
\hline
\end{tabular}

where $k_{c}{ }^{2}$ is the coefficient of permeability calculated using equation $2(\mathrm{~m} / \mathrm{s})$ and $k_{c}{ }^{3}$ is the coefficient of permeability calculated using equation $3(\mathrm{~m} / \mathrm{s})$.

\subsection{Results}

\section{1) Excess pore pressure distribution}

During double drainage consolidation tests, the excess pore pressure ( $\left.u_{\text {excess }}\right)$ occurs at the middepth of the soil profile. For accurate and precise determination of the compressibility parameters and $u_{\text {excess }}$, the American and British Standard recommended a D/H ratio of 2.5 and 4 respectively. Theoretically, the excess pore pressure is obtained from the relationship of effective and total stress. $u_{\text {excess }}$ is also obtained by multiplying the unit weight of water by the soil height [8]. Data are presented in terms of three drainage scenarios with $k_{c}$ : Case1 (horizontal drainage), Case 2 (vertical and horizontal drainage) and vertical drainage.

\section{2) Estimated coefficient of permeability $\left(k_{e}\right)$}

[5] investigation revealed that at $D / H$ less than 2, fluctuations in behaviour are found as compared to $D / H$ greater than 2 . The minor difference with the Standard is not significant as the findings still validate that stated in the British and American Standard. Figure 1 shows the behaviour of the soils using the estimated $\mathrm{k}$ value compared the experimental outcome. From Figure $1, D / H$ greater than 2 shows a less significant difference in the rate of consolidation. There is an important maximum difference between $D / H$ less than 2 and greater than 2 , 
indicating the important of selecting the appropriate value for the $D / H$ ratio as per the Standard. Similar patterns were observed at load increment ranging between $110 \mathrm{kPa}$ to $276 \mathrm{kPa}$.

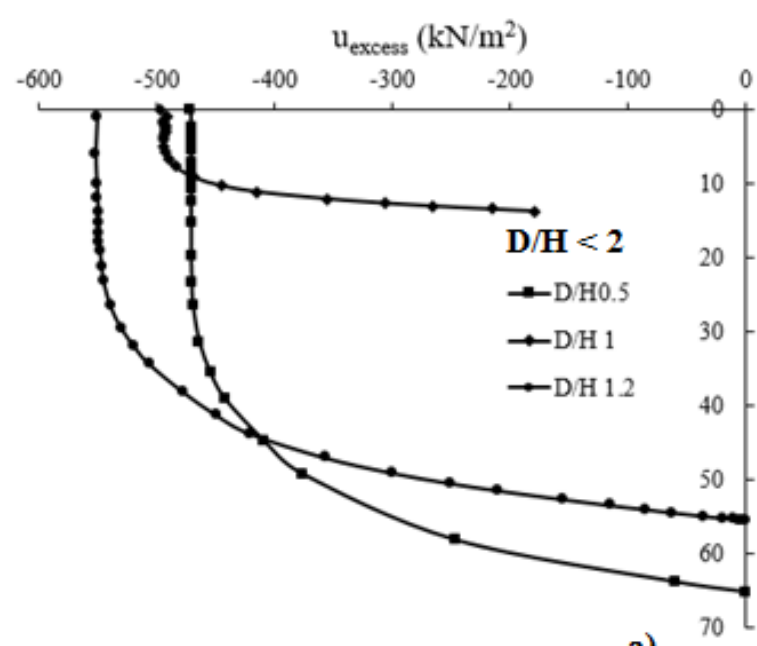

a)
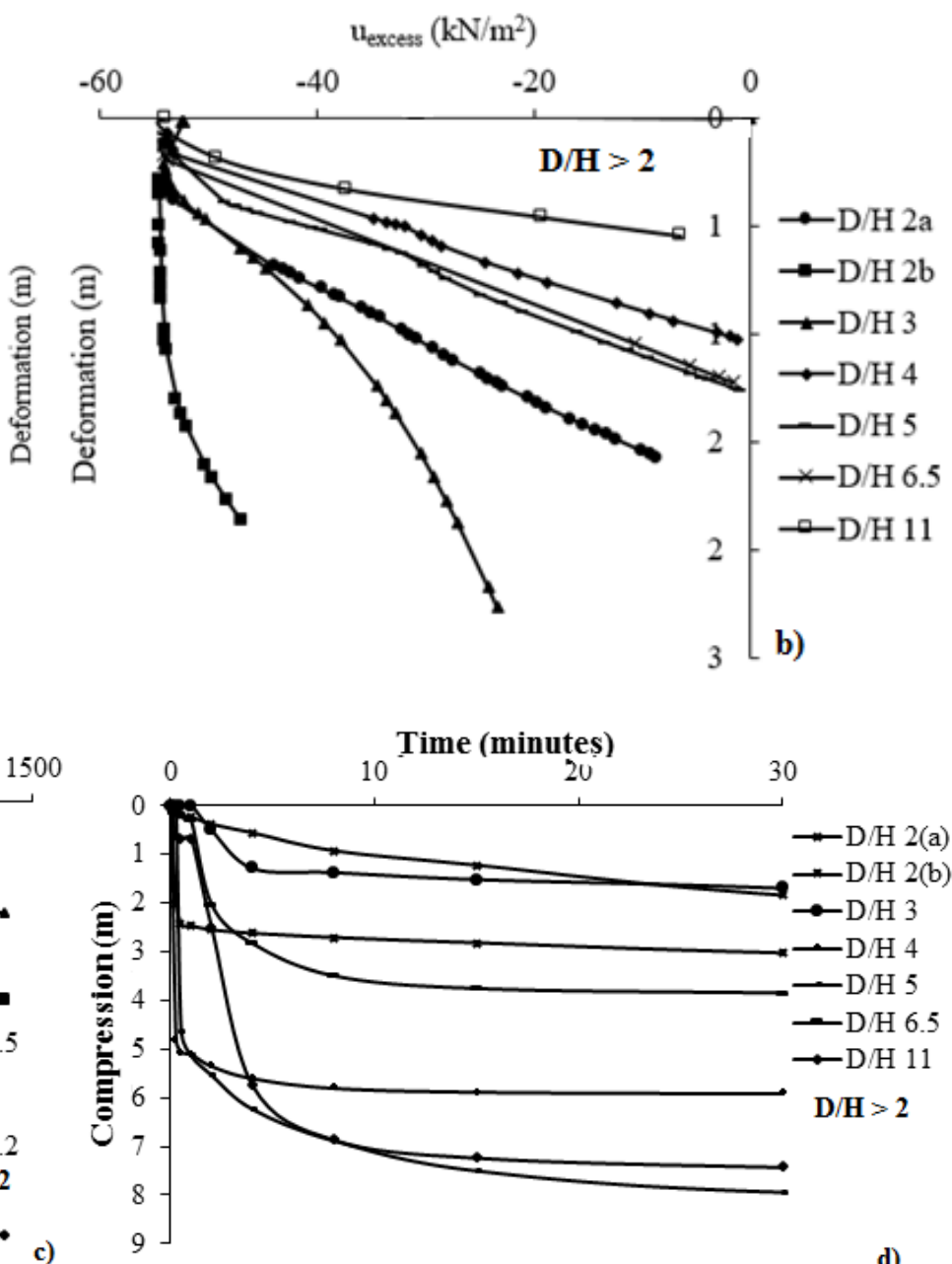

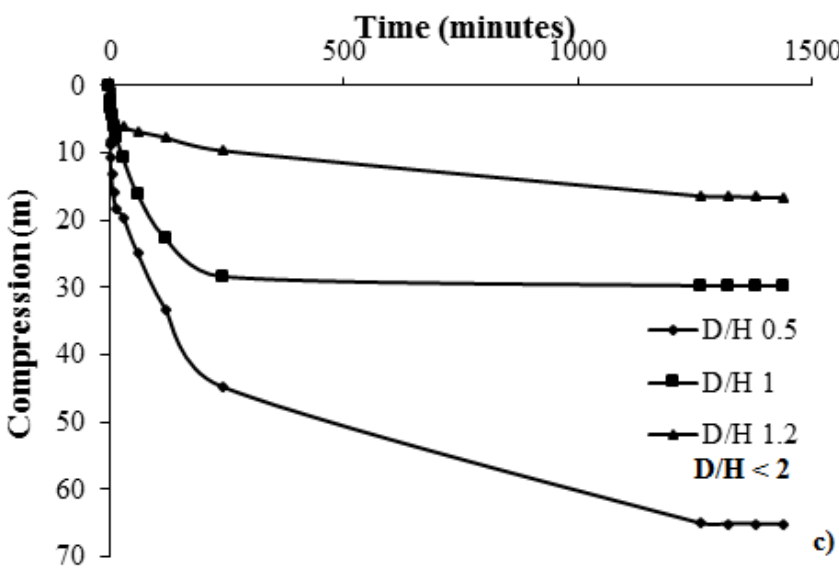

Figure 1: Numerical and experimental analysis of the effect of sample scale on on fine grained soil using the estimated coefficient of permeability; a) and b) FEM and c) and

\section{d) Experimental}

\section{3) Calculated coefficient of permeability $\left(\boldsymbol{k}_{c}\right)$}

It was noted that the estimated coefficient of permeability $\left(k_{e}\right)$ presented identical and consistent result for both drainage scenarios (case 1 and 2) (Figure 1). However, when the calculated coefficient of permeability $\left(k_{c}^{2}\right)$ was used during simulation, a drastic change in performance was noted in case 1 and 2. Figures 2 to 5 also complements soil behaviour under sample height and $D / H$ ratio scale. $D S 150 H 130$ (Figure $2 \mathrm{a}$ ) was further corrected using a higher strength value of $150 \mathrm{kN} / \mathrm{m}^{2}$. This was found to be successful only in case 2 when using $k_{c}^{2}$. At DS250H200, the soil collapsed before the consolidation phase calculation was completed in 
case 1 (depicted in Figure 2c) and ended when a strength value of $200 \mathrm{kN} / \mathrm{m}^{2}$ was used in case 2. $D S 100 H 200$ (Figure 2d) strength value of $55 \mathrm{kN} / \mathrm{m}^{2}$ was used in case 2 , and case 1 was corrected using $200 \mathrm{kN} / \mathrm{m}^{2}$.

Calculated coefficient of permeability $k_{c}{ }^{2}$ and $k_{c}{ }^{3}$ obtained using equation 2 and 3 respectively were used during the analysis. From the parameters depicted in Table 3, the relationship of the soil behaviour is shown in Figures 2 to 5 . Figure 2 follows the same pattern as Figure 1 except at $D / H 1.2(D S 250 H 200)$. This array contradicts findings in Figure 1 where at $D / H$ greater than 2 , accurate $u_{\text {excess }}$ illustration was observed. There is a maximum difference of $1 \%$ and $5 \%$ at $D / H \quad 0.5(D S 100 H 200)$ and $1(D S 150 H 130)$ using $k_{c}{ }^{2}$ and $k_{c}{ }^{3}$ respectively. $D / H 1.2$ (DS25OH2OO) at $k_{c}^{2}$ is $89 \%$ less than that achieved using $k_{e}$.
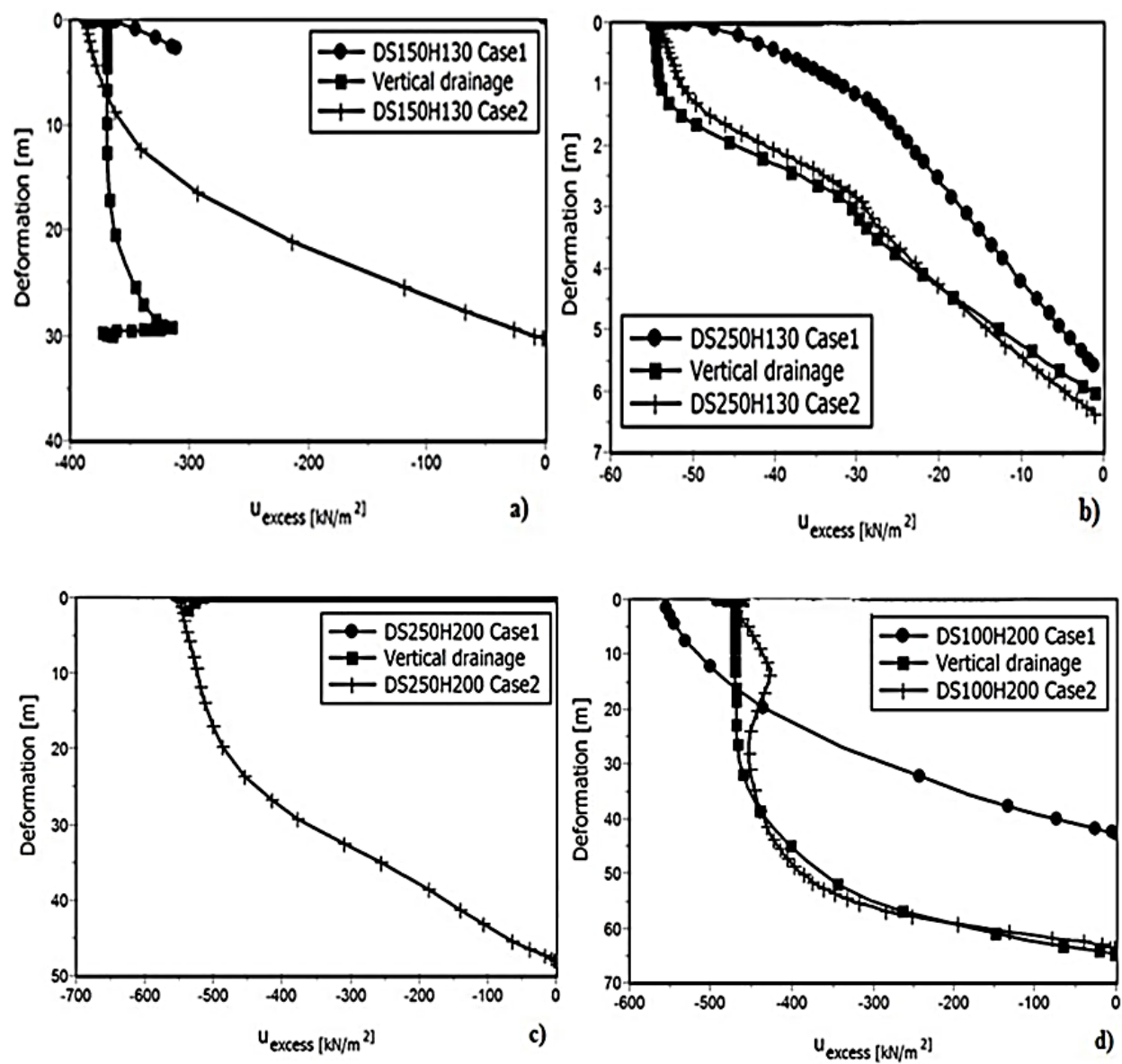

Figure 2: Effect of different drainage scenarios under the calculated coefficient of permeability $\left(k_{c}^{2}\right)$ at $55 \mathrm{kPa}$ (Where: case 1 is the horizontal drainage scenario and case 2 is combined vertical and horizontal drainage) 

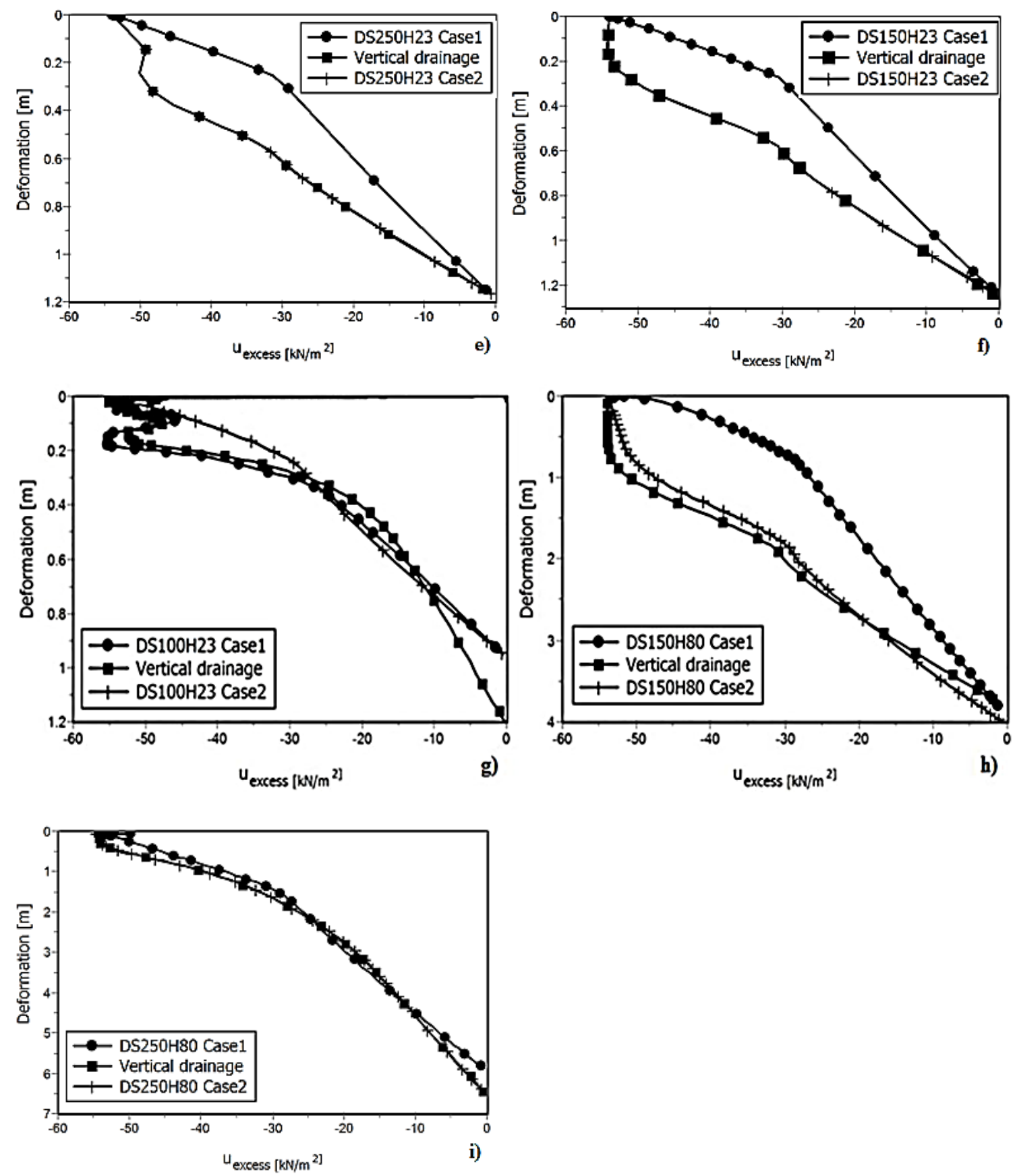

Figure 3: Effect of different drainage scenarios under the calculated coefficient of permeability $\left(k_{c}^{2}\right)$ at $55 \mathrm{kPa}$ (continue) (Where: case 1 is the horizontal drainage scenario and case 2 is combined vertical and horizontal drainage)

Case 2 and vertical drainage was found to produce identical trends at $\mathrm{DS} 250 \mathrm{H} 130, \mathrm{DS} 250 \mathrm{H} 23$, $D S 15 O H 23, D S 150 H 80$ and $D S 250 H 80$, but $D S 10 O H 23$ has a maximum difference of $18 \%$. On the other hand, DS25OH130 and DS1OOH2OO have a maximum difference of $8 \%$ and $9 \%$ respectively between the vertical drainage and case 2 . Case 1 does not correlate well with the 
remaining drainage condition at all sample diameter scale except at $D S 100 H 23$ where the difference is disproportional.

Case 1 drainage type was not successfully applied with $k_{c}{ }^{2}$ as shown in Figure $4 \mathrm{a}, \mathrm{b}, \mathrm{c}, \mathrm{d}$ and Figure $5 \mathrm{e}$, where the variation in $D / H=1,2(\mathrm{~b}), 1.2,0.5$ and 11 respectively is inconclusive. The failure of case 1 was due to $N A N$ (Not a Number) found. $N a N$ only occurs when the field elements are in a plastic state. As a resolution, the strength of the soil material is increased, or a linear elastic soil material could be used [9]. This is because during consolidation, as the load increases, the soil behaviour changes from elastic to plastic which is affected by the strength and compressibility characteristics of the soils. Therefore, the significant variation between the drainage type in both Figures 2 to 5 are mainly incorporated with sample scale and the permeability factors. This is because, in PLAXIS, the consolidation is modelled using the permeability value. Hence, this findings shows not only the importance of the permeability values but that of the effect of drainage type at several $D S$.
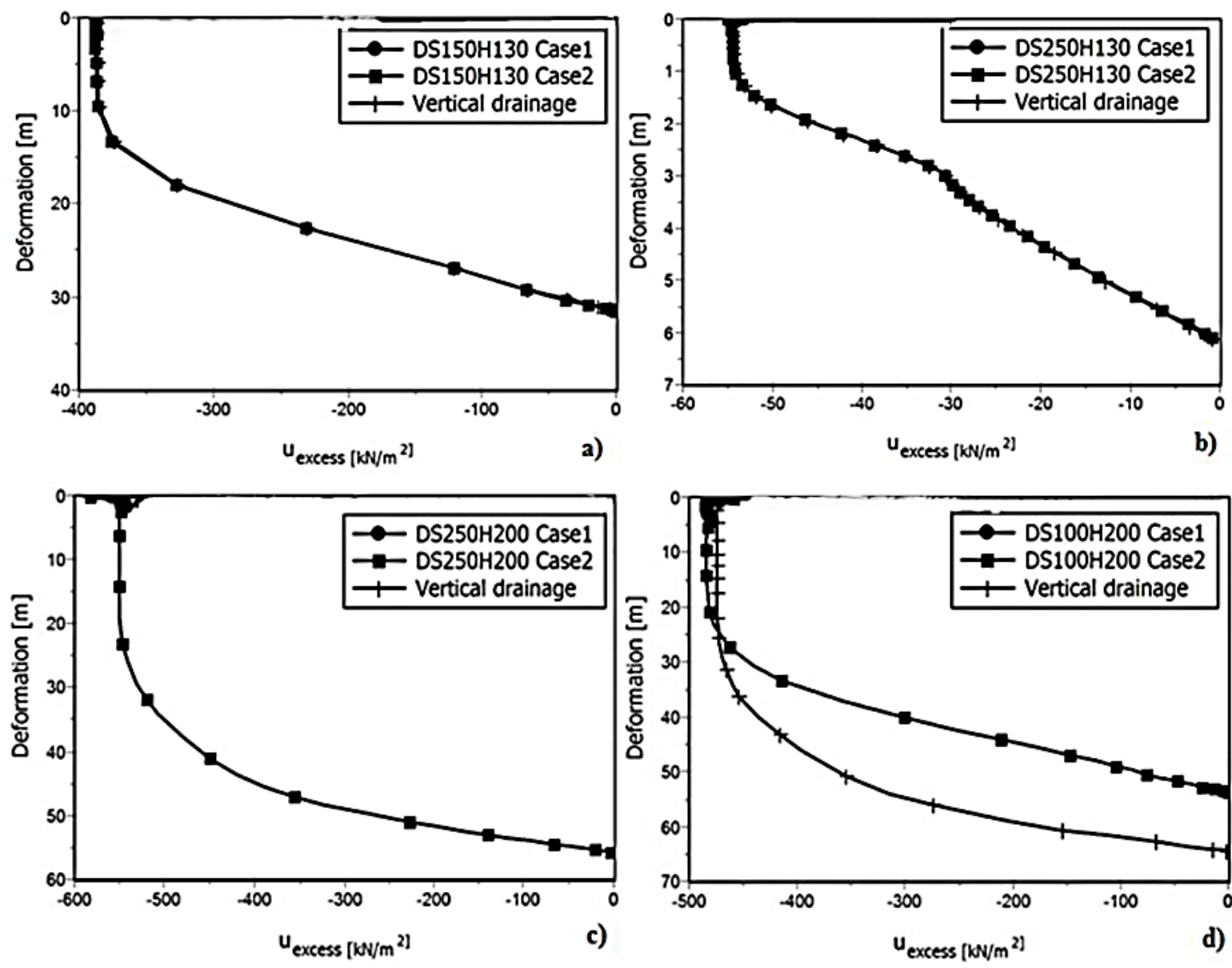

Figure 4: Effect of various drainage scenarios under the calculated coefficient of permeability $\left(k_{c}{ }^{3}\right)$ at $55 \mathrm{kPa}$ (Where: case 1 is the horizontal drainage scenario and case 2 is combined vertical and horizontal drainage) 

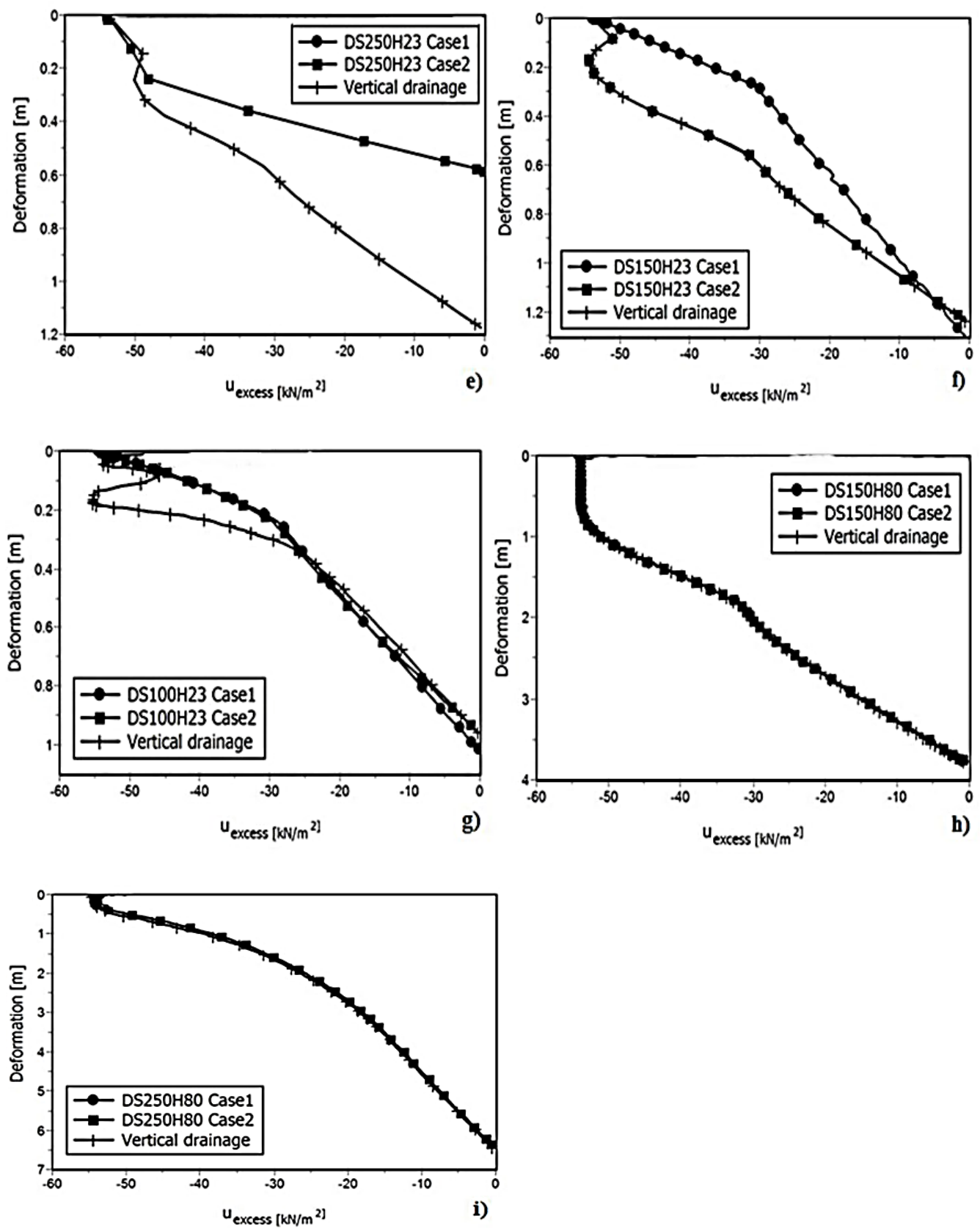

Figure 5: Effect of various drainage scenarios under the calculated coefficient of permeability $\left(k_{c}{ }^{3}\right)$ at $55 \mathrm{kPa}$ (continue) (Where: case 1 is the horizontal drainage scenario and case 2 is combined vertical and horizontal drainage)

The $c_{v}$ value was obtained using the Taylor's method at $55 \mathrm{kPa}$ in the calculation of $k . c_{v}$ values ranged from $0.75-13.7 \mathrm{~m}^{2} / \mathrm{yr}$ and $\mathrm{m}_{\mathrm{v}}$ from $0.0007-0.006 \mathrm{~m}^{2} / \mathrm{MN}$. There is a $57 \%$ decrease in excess pore pressure at $\mathrm{D} / \mathrm{H} 0.5(\mathrm{DS} 100 \mathrm{H} 200)$ from the estimated $\mathrm{k}_{\mathrm{e}}$ value and a fluctuation in behaviour in the remaining scale. It can thus be stated that the calculated $\mathrm{k}$ value using equation 3 gives a more realistic observation at $\mathrm{D} / \mathrm{H} 0.5(\mathrm{DS} 100 \mathrm{H} 200)$. At $\mathrm{D} / \mathrm{H} 1.2(\mathrm{DS} 150 \mathrm{H} 200)$ there 
was a $99 \%$ increase in $u_{\text {excess }}$ as compared to the estimated findings. Hence, the calculated coefficient of permeability $k$ using equation 3 is not applicable where the scale is an issue $(D / H$ $<2$ and $D / H=5)$.

\section{Conclusion}

The current study evaluates the difference between the calculated and estimated coefficient of permeability $(k)$. The calculated $k_{c}$ value from equation 3 was compared with that derived by [3] using regression analysis and that estimated from PLAXIS. The findings show that, in terms of excess pore pressure and scale, equation 3 is more effective as the measured parameters reflect the soil behaviour. The estimated value presented more accurate findings at all the sample scale as compare to $k_{c}$. On the contrary, equation 2 by [3] was also valid but not at $D / H$ less than 2. Equation 3 is especially valuable to $D / H 0.5$ where excess pore pressure was faintly observed at the centre of the soil matrix. Both calculated and estimated $k$ values showed to have a negligible error in excess pore pressure. However, this error is significant on $c_{v}$ and the significance was corrected with a correction factor of 0.677 . Therefore, it was proposed that equation 2 and 3 when equated provides a new relationship for $\mathrm{c}_{\mathrm{v}}$ as shown in equation 5.

\section{REFERENCES}

1. C. Liu, and J.B. Evett, "Soils and Foundations. SI Edition," Prentice Hall, (2005).

2. F.D. Masch, and K.J. Denny, "Grain size distribution and its effect on permeability," Water Resources Research, 2(4): 665 - 677 (1966).

3. A. Singh, and S. Noor, "Estimation of soil permeability using soil index properties," International Journal of Latest Trends in Engineering and Technology (IJLTET), 1(4): 31 33 (2012).

4. R.G. Shepherd, "Correlations of permeability and grain size," Ground water, 27 (5): 633 638 (1989).

5. T.N. Rosine, and T.T. Sabbagh, "The impact of the diameter to height ratio on the compressibility parameters of saturated fine-grained soils," International Journal of Research and Engineering Technology, 4(5): 8 - 19 (2015).

6. British Standard, BS1377: PART 2, "Methods of tests of soils for civil engineering purposes - Classification Tests," (1990).

7. American Society For Testing And Materials, 'D4318', "Standard test method for liquid limit," Plastic limit and plasticity index of soils, (2010).

8. J.E. Bowles, J.E, "Foundation analysis and design," Second edition, McGraw-hill Kogakusha Ltd (1977)

9. PLAXIS 2D, "Reference manual," Essential for geotechnical engineering, (2011). 